Western University Scholarship@Western

1992

\title{
Efficiency of Comparative Negligence: A Game Theoretic Analysis
}

Tai-Yeong Chung

Follow this and additional works at: https://ir.lib.uwo.ca/economicsresrpt

Part of the Economics Commons

Citation of this paper:

Chung, Tai-Yeong. "Efficiency of Comparative Negligence: A Game Theoretic Analysis." Department of Economics Research Reports, 9215. London, ON: Department of Economics, University of Western Ontario (1992). 


\section{RESEARCH REPORT 9215 \\ Efflclency of Comparative Neglisencer A Game Theoretic Analyel. by \\ Te1-Yeone Chuns Department of Economics Librory \\ DEC \& 1! 1992 \\ University of Westam Ontario}

November 1992

Depertment of Economice

Sociel science Centre

UnIvere1ty of Wertern Ontar10

London, Ontar1o, Canada 


\title{
Efficiency of Comparative Negligence: \\ A Game Theoretic Analysis
}

\author{
by \\ Tai-Yeong Chung
}

First Version, May 28, 1991

Revised, November 20, 1992

\author{
Department of Economics \\ Social Science Centre \\ University of Western Ontario \\ London, Ontario N6A 5C2 \\ Canada
}




\title{
EFFICIENCY OF COMPARATIVE NEGLIGENCE : A GAME THEORETIC ANALYSIS
}

\author{
TAI-YEONG CHUNG*
}

$T_{\text {he widespread shift from contributory negligence to comparative negligence in the }}$ twentieth century has spurred scholars in law and economics to examine the strength and weakness of alternative negligence rules. The conventional wisdom on this issue is that contributory negligence is economically more efficient than comparative negligence. ${ }^{1}$ This result has led to several scholars to investigate other environments in which the efficiency of comparative negligence can be shown. Their central conclusions can be summarized as follows. First, in a full information environment, if the legal standard of care is set at the efficient level of care, then any form of the negligence rules provide correct incentives for efficient precaution. ${ }^{2}$ Second, in a limited information environment, comparative negligence can be more efficient than contributory negligence. $^{3}$ Third, comparative negligence rule entails higher administration costs. ${ }^{4}$ Fourth, comparative negligence can be justified based on fairness or equity concern. 5

Daniel Orr cast another vote for comparative negligence by providing a game theoretic analysis in which relative efficiency of comparative negligence and contributory negligence were examined. ${ }^{6}$ Orr showed that comparative negligence is more efficient than contributory negligence in both unilateral and interactive precaution cases. His result is puzzling because it was shown in a full information environment and thus is not consistent with the first central conclusion of the existing literature. It is not clear whether the existing literature is flawed or whether Orr identified a very special condition under which his argument holds. Are those assumptions made by Orr 
consistent with the ones made in the existing literature ? Is there something else that led Orr to make a seemingly contradictory conclusion?

The purpose of this Article is to clarify these issues by providing a correct game theoretic analysis of negligence rules. The Article is organized as follows. In Section I, I construct a formal model of negligence. In Section II, I argue that the names of two strategies of each party in Orr's model (caution and negligence) generate confusion. They should have been taking a precaution and taking no precaution. Each of the parties can only decide whether to take a precaution or not. It is only the courts that can determine whether an action chosen by a party is negligent or not. As Orr correctly stated, negligence is a failure to take precaution in the presence of a duty to do so. When no such a duty is required, taking no precaution cannot be negligent behavior. This misnomer forced Orr implicitly to assume that the legal standard of care is set at an inefficient level, contrary to his intention of assuming that the legal standard of care is set at the efficient level of care.

In Section III, I show that one of Orr's result crucially depends on his implicit assumption that the legal standard of care is inefficient. If the legal standard of care is set at an efficient level in Orr's model, then, in the unilateral precaution case, negligence and comparative negligence generally yield the same efficient outcome. Furthermore, for some values of parameters, comparative negligence is less efficient than contributory negligence.

In Section IV, I give a different interpretation of the result for the case of interactive precaution. In this case, Orr's misnomer or the implicit assumption does not change the result of the model. Orr argued that comparative negligence provides a stronger incentive for efficient precautions than contributory negligence does. My criticism is that the degree of strengthening is negligible.

Section V contains concluding remarks. 


\section{Model}

Consider two parties to an accident, called injurer (R) and injuree (E). Let $A$ denote the expected accident cost in the absence of effective precaution by either party. Each party can take some precaution to reduce the expected cost of the accident. For simplicity, consider two (pure) strategies for each party. The strategy $e$ for $\mathrm{E}$ is either taking a precaution (denoted by $e_{1}$ ) or taking no precaution (denoted by $e_{0}$ ). Similarly, the strategy $r$ for $R$ is either taking a precaution (denoted by $r_{1}$ ) or taking no precaution (denoted by $r_{0}$ ). Assume that the parties make precaution decision independently and simultaneously. Thus, each party has to make his own precaution decision without knowing the other party's choice.?

Let $p$ denote the factor by which cost is reduced through precaution by either or both parties. In general, $p$ will be a function of both $e$ and $r$, that is, $p(e, r)$. Taking precaution incurs some direct cost to parties. Let $c^{E}(e)$ denote the cost to $\mathrm{E}$ of taking precaution $e$. Similarly, let $c^{R}(r)$ denote the cost to $\mathrm{R}$ of taking precaution $r$. For notational convenience, let $c^{E}\left(e_{1}\right)=c_{e}$, and $c^{R}\left(r_{1}\right)=c_{r}$. It is assumed without loss of generality that $c^{E}\left(e_{0}\right)=0$, and $c^{R}\left(r_{0}\right)=0$.

A pair of precaution levels, denoted by $\left(e^{*}, r^{*}\right)$ is said to be socially efficient if $\left(e^{*}, r^{*}\right)$ minimize the sum of expected accident cost and precaution costs. ${ }^{8}$ Formally,

$$
\left(e^{*}, r^{*}\right) \text { minimizes } p(e, r) A+c^{E}(e)+c^{R}(r)
$$

By definition, $e^{*}$ is a socially efficient level of precaution by $\mathrm{E}$ if $\mathrm{R}$ is choosing $r^{*}$. Similarly, $r^{*}$ is a socially efficient level of precaution by $\mathrm{R}$ if $\mathrm{E}$ is choosing $e^{*}$. Note that there could be multiple solutions to the minimization problem. 
The goal of designing a legal rule in this context is to induce the parties to take the efficient precautions to minimize the sum of expected accident cost and precaution cost. Different legal rules create different framework or "games" in which the parties interact in choosing their precaution levels.9 I assume that at the time of choosing precautions the parties know which legal rule will be ex post used by the court to allocate accident costs. Without this assumption, the incentive effects of legal rules cannot be examined.

Two alternative negligence rules are considered: contributory negligence and comparative negligence. ${ }^{10}$ A party's precaution decision is said to be negligent if it is short of a legal standard of care which is usually assumed to be a socially efficient level of precaution. Thus, $\mathrm{R}$ is said to be negligent if $r<r^{*}$. Given that $\mathrm{R}$ is negligent, $\mathrm{E}$ is said to be contributorily negligent if $e<e^{*}$. Thus, under contributory negligence, if $r<$ $r^{*}$ and $e<e^{*}$, then $\mathrm{E}$ has to assume all the accident cost (in addition to his own cost of precaution). On the other hand, under comparative negligence, the cost of accident is shared between two parties when both parties are negligent. Let $\gamma$ denote E's share of the accident cost in that case.

\section{Orr's Analysis}

The purpose of this section is to identify clearly the conditions which derive Orr's result, and thus provide a basis upon which I examine them in later sections. Consider the following assumptions which Orr made in his analysis.

Assumption 1. Precaution is unilateral: formally, $p\left(e_{0}, r_{0}\right)=1$ and $p\left(e_{1}, r_{0}\right)=p\left(e_{0}, r_{1}\right)=$ $p\left(e_{1}, r_{1}\right)=p$, where $p$ is a constant whose value is strictly between 0 and 1 . 
Assumption 1 says that precaution is unilateral when it is equally effective whether provided by either party or by both parties to an accident. ${ }^{11}$ An alternative precaution technology, namely interactive precaution, is considered in Section IV.

I further assume (as Orr did) that the parties face the same cost of precaution $c$, (i.e. $c_{e}=c_{r}=c$ ). Relaxing this assumption will not change any of my claims. To make the problem interesting, assume that $p A>c>0$ and $p A+c<A$. In words, taking precaution is cost-justified given that the other party does not take precaution.

Given these assumptions, Assumption 1 guarantees that the game will have two socially efficient outcomes ( precaution taken by only one of the parties ).12 Formally, both $\left(e_{1}, r_{0}\right)$ and $\left(e_{0}, r_{1}\right)$ are efficient. For example, if the injuree $\mathrm{E}$ did take precaution, then it is not negligent for the injurer $\mathbf{R}$ not to take precaution since it is a socially efficient precaution behavior. Note that it is inefficient for both parties to take precaution or for both parties not to take any precaution.

It is unfortunate that Orr named two (pure) strategies of the parties as caution and negligence. In other words, it amounts to saying that taking no precaution is always determined (by the courts) to be negligent. Therefore, Orr was forced to implicitly make the following unusual assumption.

Assumption 2. The legal standard of care is set at such level that both parties take precaution, that is, $r^{*}=r_{1}$ and $e^{*}=e_{1}$.

The legal standard of precaution in Assumption 2 requires both parties to take precaution, which is inefficient given Assumption 1. It could be an efficient standard, however, under other environments, for example, with interactive precaution. Under Assumption 2, the contributory negligence rule says that $\mathrm{R}$ is negligent if and only if $e=$ 
$e_{1}$ and $r=r_{0}$. This generates Game 1 in Orr's paper and supports his argument for comparative negligence.

Under these two assumptions, Orr showed that the game governed by contributory negligence does not have any pure strategy Nash equilibrium, and it has a unique mixed strategy equilibrium which results in a socially inefficient precaution behavior. For both parties take precaution with a positive probability in the mixed strategy equilibrium. On the other hand, comparative negligence induces a pure strategy equilibrium which is efficient. Hence, Orr argued that comparative negligence has decisive advantages over contributory negligence.

Assumption 2 is unusual given that most analyses of negligence rules in the existing literature assumed that the legal standard of care is set at an efficient level. It is shown in Section III that when the legal standard of care is set at an efficient level, contributory negligence is always efficient, and comparative negligence could be inefficient. Assumption 2 is also problematic because it supposes only one side of the inefficiency, namely, too strict standards. It is shown in the next section that when legal standard of care is too loose, Orr's result cannot be obtained.

In the following section, I consider Orr's model under the alternative assumption that the legal standard of care is set at an efficient level and show that comparative negligence rule is no more efficient than contributory negligence rule.

\section{When the legal standard of precaution is efficient: Unilateral Precaution}

Following the convention in the existing literature, Assumption 2 is replaced by Assumption $2 \mathrm{~N}$ throughout this section. 
Assumption 2N. The legal standard of care is set at an efficient level.

This section compares the efficiency properties of two negligence rules under Assumption 1 and $2 \mathrm{~N}$. Therefore, the legal standard of care requires that only one of the parties takes precaution, that is, $\left(e^{*}, r^{*}\right)=\left(e_{1}, r_{0}\right)$ or $\left(e_{0}, r_{1}\right)$. In particular, when $\mathrm{E}$ takes precaution and $\mathbf{R}$ takes no precaution, $\mathbf{R}$ is not negligent because his precaution is taken at an efficient level. ${ }^{13}$ Thus, the cost of accident must be assumed by $\mathrm{E}$ with final payoffs $p A+C$ for $\mathrm{E}$ and $\mathbf{0}$ for $\mathrm{R}$. The corresponding new game under Assumption $2 \mathrm{~N}$ is shown as Game 1.

-. Place < Game $1>$ about here -.

Game 1 has a unique Nash equilibrium in which $R$ takes no precaution and $E$ takes precaution. ${ }^{14}$ In particular, taking no precaution is a dominant strategy for R..$^{15}$ Given this fact, taking precaution is optimal for $\mathrm{E}$. The expected cost resulting from the equilibrium is $p A+c$ for $\mathrm{E}$ and $\mathbf{0}$ for $\mathrm{R}$. Thus, contributory negligence leads to socially efficient precaution behavior even though $\mathrm{E}$ must bear all the expected cost from the accident. ${ }^{16}$

Now, consider the game created by the comparative negligence under Assumption $2 \mathrm{~N}$. The only difference from Game 1 will be in the case where both $\mathrm{E}$ and $\mathbf{R}$ take no precaution. 
Injurer's choice $(\mathbf{R})$

\begin{tabular}{|c|c|c|}
\hline & $r_{1}$ & $r_{0}$ \\
\hline Iniuree's choice $(E)^{e_{1}}$ & $p A+c, c$ & $p A+c, \quad 0$ \\
\hline$e_{0}$ & $p A, c$ & $A, 0$ \\
\hline
\end{tabular}

< Game 1: Contributory Negligence with Efficient Standard of Care > 
-- Place < Game 2 > about here --

As Orr did, I assume that $(1-\gamma) A>c$. In words, the liability cost to $\mathrm{R}$ when both parties are negligent under comparative negligence is greater than the common precaution cost. Then, Game 2 has a Nash equilibrium in which $E$ takes no precaution and $\mathrm{R}$ takes precaution (its payoff is $p A$ for $\mathrm{E}$ and $c$ for $\mathrm{R}$ ). If $\gamma A<p A+c$, then it is the unique Nash equilibrium of Game 2. If $\gamma A \geq p A+c$, then there are two more equilibrium: another pure strategy Nash equilibrium and a mixed strategy equilibrium. In that case, the existence of multiple equilibria poses a selection or coordination problem to the parties.

In the new pure strategy Nash equilibrium, $E$ takes precaution and $R$ takes no precaution with its payoff $p A+c$ for $\mathrm{E}$ and 0 for $\mathrm{R}$. Therefore, if the parties coordinate themselves to play one of the two pure strategy equilibria, then it leads to socially efficient precaution behavior. On the other hand, the mixed strategy equilibrium involves some inefficient behavior since both parties take precaution with a positive probability. ${ }^{17}$

If $\gamma$ is small enough, comparative negligence rule also leads to a socially efficient precaution, but the outcome is not the same as under contributory negligence. Therefore, the net change from contributory to comparative negligence is not a loss of efficiency, but a different allocation of costs. On the other hand, if the injuree E's share $\gamma$ is so large that his liability cost when both parties are negligent is greater than the sum of accident and precaution cost $(\gamma \geq p+c / A)$, then there could be an efficiency loss 


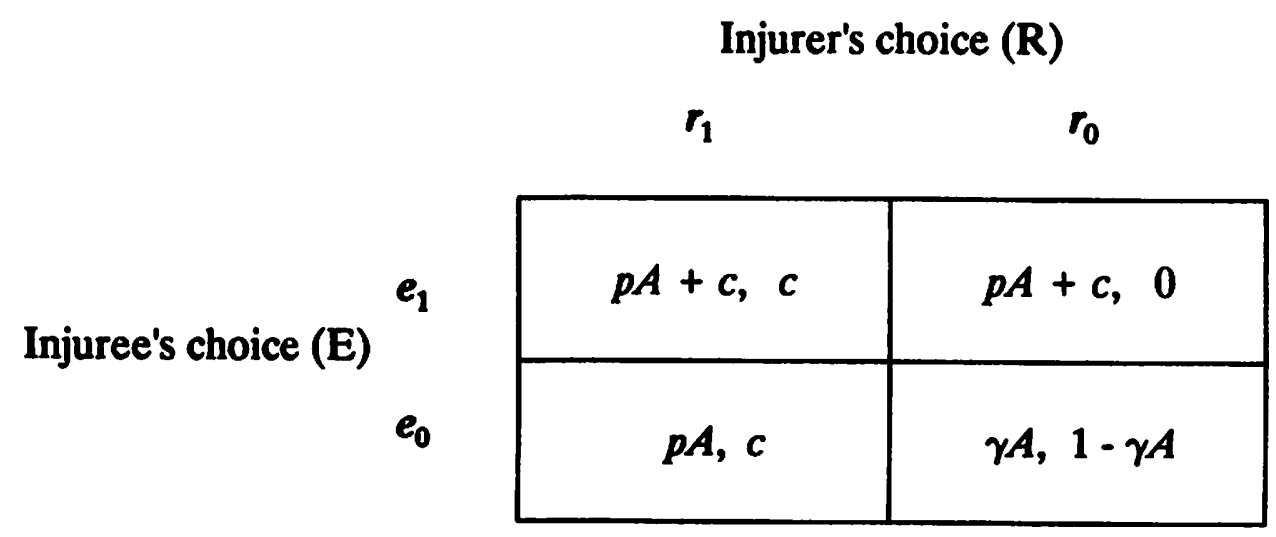

< Game 2: Comparative Negligence with Efficient Standard of Care > 
due to the mixed strategy equilibrium. This is the opposite result from Orr's argument for comparative negligence.

Orr's result may be interpreted as follows: comparative negligence could be more efficient than contributory negligence when the legal standard of care is set at an inefficient level. This does not mean, however, that whenever the legal standard of care is inefficient, comparative negligence is always better than contributory negligence. In fact, if it is assumed that the legal standard of care is loose in the sense that $e^{*}=e_{0}$ and $r^{*}=r_{0}$, then it can be shown that contributory negligence induces the same efficient behavior as comparative negligence does.

\section{When the legal standard of precaution is emcient: Interactive Precaution}

So far, only the case of unilateral precaution has been considered. Now consider the case interactive precaution. When precaution is interactive, precaution taken by each party reduces expected cost even if the other party is also taking precaution. Following Orr, I make the following assumption which replaces Assumption 1N. I continue to make Assumption 2N.

Assumption 1N. (Interactive precaution)

$$
\begin{aligned}
p(e, r) & =1 & \text { if } e=e_{0}, r=r_{0} . \\
& =p & \text { if } e=e_{1}, r=r_{0} . \\
& =q & \text { if } e=e_{0}, r=r_{1} . \\
& =p^{\wedge} q & \text { if } e=e_{1}, r=r_{1} .
\end{aligned}
$$


To make the problem interesting, assume that $p<1, q<1$, and $\left(p^{\wedge} q\right) A+c<$ $p A,\left(p^{\wedge} q\right) A+c<q A$ as Orr did. Given the assumption, it is efficient for both parties to take precaution. Thus, the legal standard of precaution, if set at an efficient level, must be $e_{1}$ for $\mathrm{E}$ and $r_{1}$ for $\mathrm{R}$. Therefore, with the interactive precaution technology, Assumption 2 is not inconsistent with Assumption 2N. In fact, the formal analysis of this section will be exactly the same as Orr's analysis under Assumption 2. The distinction would be on the interpretation of the results.

Consider the game created under contributory negligence.

-- Place < Game 3 > about here -.

Game 3 has a unique Nash equilibrium $\left(e_{1}, r_{1}\right)$. In particular, $e_{1}$ is a dominant strategy for $\mathrm{E}$ since $\left(p^{\wedge} q\right) A+c<q A$ and $c<A$ by assumption. Given this fact, $r_{1}$ is the optimal strategy for $\mathrm{R}$ since $c<p A$. Therefore, contributory negligence rule induces the efficient precaution behavior by both parties.

The game created by the comparative negligence rule is represented as Game 4.

-- Place < Game 4 > about here -- 


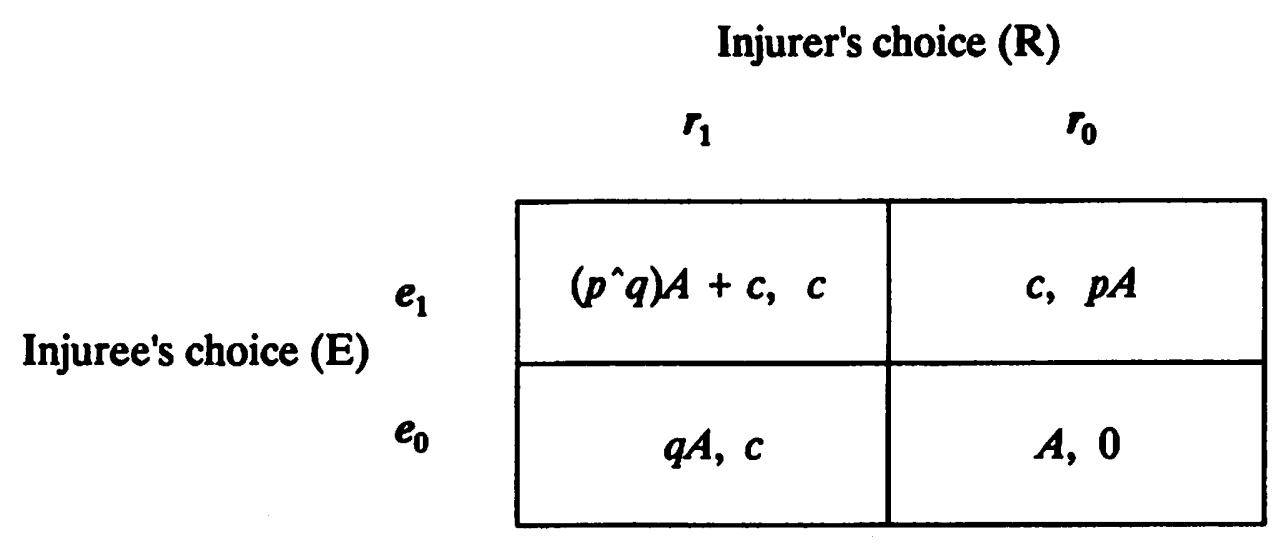

< Game 3: Contributory Negligence with Interactive Precation > 
Injurer's choice $(\mathbf{R})$

$r_{1}$

$r_{0}$

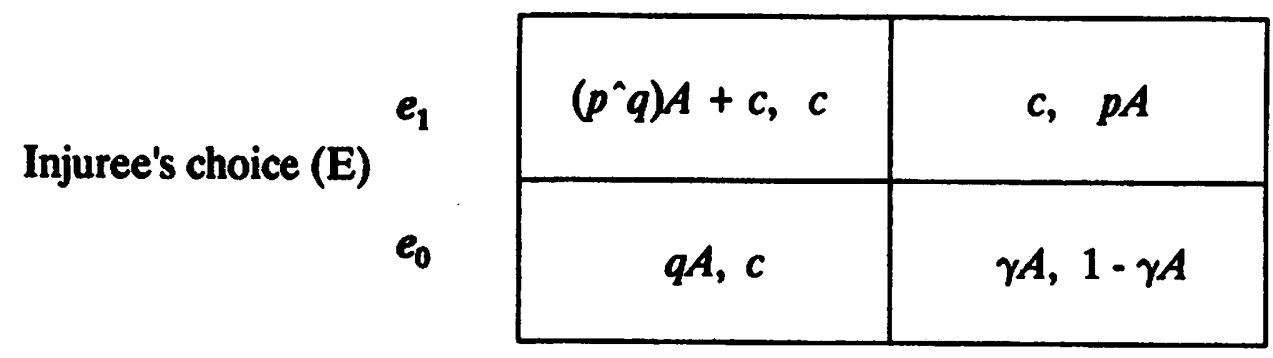

< Game 4: Comparative Negligence with Interactive Precaution > 
Recall that it is assumed in Subsection $A$ that $(1-\gamma) A>c$. Given this assumption, $r_{1}$ is a dominant strategy for $\mathrm{R}$ since $c<p A$ and $c<(1-\gamma) A$. Given this fact, $e_{1}$ is the optimal strategy for E since $\left(p^{\wedge} q\right) A+c<q A$. Therefore, Game 5 has a unique Nash equilibrium $\left(e_{1}, r_{1}\right)$ which is efficient.

Orr correctly observed that outcomes from both rules are the same. As I have already shown, both games created by contributory negligence and comparative negligence predict the exactly same equilibrium, which is also a unique Nash equilibrium. ${ }^{18}$ In Game 3 (contributory negligence), taking precaution is a dominant strategy for the injuree E, while in Game 4 (comparative negligence), taking precaution is a dominant strategy for the injurer $R$.

If one makes a further assumption (which Orr did not) that $c<\gamma A$, then under comparative negligence, taking precaution also becomes a dominant strategy for $\mathrm{E}$. This may be viewed as strengthening the power of comparative negligence. Recall, however, that contributory negligence implements the same efficient outcome as a unique Nash equilibrium in which $\mathrm{E}$ chooses a dominant strategy. As along as $\mathbf{R}$ is rational, therefore, there is hardly any difference between two rules in this case. ${ }^{19}$

In summary, with the interactive precaution, both rules of negligence induce the efficient precaution behavior. Thus, one cannot claim that when precaution is interactive, the comparative negligence rule is more efficient than the contributory negligence rule. 


\section{Conclusion}

Orr's result that, in a full information environment, comparative negligence is more efficient than contributory negligence has been criticized on two accounts: (i) Orr's result for the unilateral precaution case crucially depends on the unusual assumption that the legal standard of care is inefficient, which is implicit in his naming of strategies, and (ii) Orr's result for the interactive precaution case is derived from too much emphasis on the technical difference between equilibria, which turns out to be negligible.

This leaves us with the existing result that when the legal standard is set at the efficient level, negligence and comparative negligence create incentives fòr efficient precaution. Thus, there is no efficiency motivation for favoring one rule over the other. This suggests that if comparative negligence has any advantage over contributory negligence, one should look at limited information environments; or other aspects of the rules such as fairness concern. 


\section{FOOTNOTES}

- Assistant Professor of Economics, University of Western Ontario. Comments on earlier drafts from Danial Orr and William Landes were very helpful, as were conversations with Niels Anthonisen and Abhijit Sengupta.

1 John Prather Brown, Toward an Economic Theory of Liability, 2 J. Legal Stud. 323 (1973), and Richard A. Posner, Economic Analysis of Law (2d ed. 1977) at 123-24.

2 Robert D. Cooter \& Thomas S. Ulen, The Economic Case for Comparative Negligence, 61 N.Y.U.L.Rev. 1067 (1986), David Haddock \& Christoper Curran, An Economic Theory of Comparative Negligence, 14 J. Legal Stud. 49 (1985), William M. Landes \& Richard A. Posner, The Economic Structure of Tort Law (1987) at 80-82, and Richard A. Posner, Economic Analysis of Law (3d ed. 1986) at 156-167.

3 Cooter \& Ulen, supra note 2 (comparative negligence is superior to contributory negligence when injurers and victims bear risk and there is evidentiary uncertainty), Haddock \& Curran, supra note 2 (even though firm conclusions cannot be made, as errors regarding efficient caretaking costs grow, the scale is tilted toward comparative negligence), and Daniel L. Rubinfield, The Efficiency of Comparative Negligence, $16 \mathrm{~J}$. Legal Stud. 375 (1987) (comparative negligence can improve on contributory negligence when the standard of care is the same for all injurers and when injurers differ in their costs of taking care).

4 Posner, supra note 1 (comparative negligence entails higher administration costs).

5 Cooter \& Ulen, supra note 2 (the adoption of comparative negligence can be justified on grounds of horizontal equity).

6 Daniel Orr, The Superiority of Comparative Negligence: Another Vote, 55 J. Legal Stud. 119 (1991) 
7 This assumption justifies the use of simultaneous move strategic form games in modeling the situation.

8 To be consistent with Orr's model, administrative costs of alternative negligence rules are ignored in the Article.

9 For an excellent introductory sketchy of game theory, see Avery Katz, The Strategic Structure of Offer and Acceptance: Game Theory and the Law of Contract Formation, 89 Michigan L. Rev. 215 (1990).

10 The negligence rule with a defense of contributory negligence is abbreviated as contributory negligence.

11 Unilateral precaution is sometimes called "alternative care", Landes \& Posner, supra note 2 , at 60-61.

12 When either (i) precaution is interactive or (ii) precaution costs are different, there is a unique pair of efficient precaution levels.

13 This point has been observed by Posner, supra note 2, at 155 (... the law defines due care as the care that is optimal if the other party is exercising due care...) as well as by Orr supra note 6, at 121 (at law, negligence is defined as a failure to meet the standard of precaution relative to the other party's level of due care).

14 Nash equilibrium is defined as a pair of strategies such that each party's strategy is an optimal response to the strategy chosen by the other party.

15 A strategy is called as a dominant strategy for one player if it is an optimal to him regardless of the other player's choice of strategy.

16 Note that, in the particular context of unilateral precaution case, contributory negligence rule generates the same efficient outcome as no liability rule does. 
17 In the mixed strategy equilibrium, $R$ chooses taking precaution with the probability $1-\frac{c}{(\gamma-p) A}$, and $\mathrm{E}$ chooses taking precaution with the probability 1 $\frac{c}{(1-\gamma) A^{\circ}}$

18 This result was first shown in William M. Landes \& Richard A. Posner, Joint and Multiple Tortfeasors: An Economic Analysis, 9 J. Legal Stud. 517, 537-39, and n.51 (1980).

19 Precisely speaking, the only rationality requirement needed for the equivalence is that the player $\mathbf{R}$ believes with a fair certainty that his opponent $\mathbf{E}$ is rational. This is a very weak requirement which will be satisfied in Orr's model (the game posit rational players, Orr, supra note 6, at 126) 